\title{
COMUNIDADES QUILOMBOLAS E ESTÁGIO CURRICULAR SUPERVISIONADO NAS LICENCIATURAS: DIÁLOGOS POSSÍVEIS EM FREIRE
}

\author{
QUILOMBOLAS COMMUNITIES AND SUPERVISED \\ CURRICULUM INTERNSHIP IN UNDERGRADUATE \\ DEGREES: POSSIBLE DIALOGUES IN FREIRE
}

\author{
COMUNIDADES QUILOMBOLAS Y PASANTÍAS \\ CURRÍCULAS SUPERVISADAS EN PREGRADOS: \\ POSIBLES DIÁLOGOS EN FREIRE
}

\author{
Marina Graziela Feldmann \\ http://orcid.org/0000-0003-3008-2636 \\ Andréia Regina Silva Cabral Libório \\ https://orcid.org/0000-0002-7457-220X \\ Maria de Jesus Ferreira César de Albuquerque \\ http://orcid.org/0000-0003-3008-2636
}

\begin{abstract}
Resumo: O presente artigo apresenta como objetivo central discutir a presença das comunidades quilombolas e Educação Escolar Quilombola (EEQ) no Estágio Curricular Supervisionado de uma Instituição de Ensino da Rede Federal de Educação, Ciência e Tecnologia e, a partir do diálogo em Freire, descortinar possibilidades de a educação escolar quilombola ser valorizada e reconhecida no currículo escolar de formação de professores como uma viabilidade de prática profissional, bem como propiciar a emancipação dos sujeitos quilombolas, historicamente invisibilizados e excluídos. A metodologia empregada baseia-se na abordagem qualitativa, a partir de um estudo bibliográfico e de análise de documentos. Buscaram-se as contribuições dos referenciais teóricos como: Freire (1981, 1997), Feldmann (2008, 2009), Santomé (2013), García (1999), entre outros. A verificação dos dados realizou-se a partir da análise de conteúdo de Bardin (2016). A concepção de formação docente ou formação de professores que prevalece nos programas de formação, em sua maioria, limita-se ao entendimento de desenvolvimento pessoal, de formar profissionais competentes em sua área de formação com foco em apenas alguns conhecimentos, e pouco valoriza as questões relacionadas às diversidades presentes no cotidiano escolar, como a cultural. A prática do estágio curricular é de suma importância para o desenvolvimento de conhecimentos essenciais para a atuação docente, especialmente
\end{abstract}


nas diferentes modalidades de ensino como a EEQ, logo é imprescindível o desenvolvimento desses conhecimentos ao longo de todo o curso de formação de docente.

Palavras-chave: Comunidades Quilombolas. Estágio Curricular Supervisionado. Formação de Professores. Educação Escolar Quilombola.

Abstract: The main objective of this article is to discuss the presence of Quilombolas communities and QuiIombolas School Education (EEQ) in the Supervised Curriculum Internship of a Teaching Institution of the Federal Education, Science and Technology Network and, from the dialogue in Freire, unveil possibilities of quilombola school education to be valued and recognized in the school curriculum for teacher training as a feasibility of professional practice, as well as providing the emancipation of quilombolas subjects, historically invisible and excluded. The methodology used is based on a qualitative approach, based on a bibliographic study and document analysis. The contributions of theoretical references such as: Freire $(1981,1997)$, Feldmann (2008, 2009), Santomé (2013), García (1999), among others, were sought. Data verification was carried out from the content analysis of Bardin (2016). The conception of teacher training or teacher training that prevails in training programs is mostly limited to the understanding of personal development, to train competent professionals in their training area with a focus on just some knowledge, and little value is given to issues related to the diversities present in the daily school life, such as the cultural one. The practice of curricular internship is of paramount importance for the development of essential knowledge for the teaching practice, especially in different teaching modalities such as the EEQ, so it is essential to develop this knowledge throughout the entire teacher training course.

Keywords: Quilombola communities. Supervised internship. Teacher training. Quilombola School Education.

Resumen: El objetivo principal de este artículo es discutir la presencia de las comunidades quilombolas y la Educación Escolar Quilombola (EEQ) en la Pasantía Curricular Supervisada de una Institución Docente de la Red Federal de Educación, Ciencia y Tecnología y, a partir del diálogo en Freire, desvelar posibilidades de La educación escolar quilombola debe ser valorada y reconocida en el currículo escolar para la formación del profesorado como una viabilidad de la práctica profesional, además de facilitar la emancipación de las materias quilombolas, históricamente invisibles y excluidas. La metodología utilizada se basa en un enfoque cualitativo, basado en un estudio bibliográfico y análisis de documentos. Se buscaron los aportes de referentes teóricos como: Freire (1981, 1997), Feldmann (2008, 2009), Santomé (2013), García (1999), entre otros. La verificación de los datos se realizó a partir del análisis de contenido de Bardin (2016). La concepción de formación docente o formación docente que prevalece en los programas de formación se limita mayoritariamente a la comprensión del desarrollo personal, a formar profesionales competentes en su área de formación con un enfoque solo en algunos conocimientos, y se le da poco valor a las cuestiones relacionadas con las diversidades presentes en la vida escolar diaria, como la cultural. La práctica de las prácticas curriculares es de suma importancia para el desarrollo de conocimientos esenciales para la práctica docente, especialmente en diferentes modalidades de enseñanza como la EEQ, por lo que es fundamental desarrollar este conocimiento a lo largo de todo el curso de formación docente.

Palabras clave: Comunidades Quilombolas. Pasantía supervisada. Formación de profesores. Educación en la escuela Quilombola.

\section{INTRODUÇÃO}

O presente artigo discute a presença da Educação Escolar Quilombola no estágio curricular supervisionado dos cursos de Licenciatura de uma Instituição de Ensino da Rede Federal de Educação Ciência e Tecnologia. Para tanto, buscamos o diálogo em Freire por 
entendermos que a educação emancipadora necessita desenvolver a consciência crítica e humana, bem como contribuir para a intervenção crítica na realidade, assim como deve ser a prática do estágio.

A metodologia empregada baseia-se na abordagem qualitativa, a partir de um estudo bibliográfico. De acordo com Lüdke e André (1986), a abordagem qualitativa apresenta como características: como fonte direta de dados, o ambiente natural, sendo o pesquisador seu principal instrumento; os dados coletados são sobretudo descritivos; há mais preocupação com o processo do que com o produto; o "significado" que os sujeitos dão às coisas e à sua vida são focos de atenção especial do pesquisador; a análise de dados segue um processo indutivo.

Marconi e Lakatos (2003, p. 183) revelam que a pesquisa bibliográfica, ou de fontes secundárias, envolve as bibliografias publicizadas acerca do tema estudado:

[...] desde publicações avulsas, boletins, jornais, revistas, livros, pesquisas, monografias, teses, material cartográfico etc., até meios de comunicação orais: rádio, gravações em fita magnética e audiovisuais: filmes e televisão. Sua finalidade é colocar o pesquisador em contato direto com tudo o que foi escrito, dito ou filmado sobre determinado assunto, inclusive conferências seguidas de debates que tenham sido transcritos por alguma forma, quer publicadas, quer gravadas.

Buscaram-se, assim, as contribuições dos referenciais teóricos como Freire (1981), Feldmann (2009), Santomé (2013), García (1999), entre outros. A verificação dos dados realizou-se a partir da análise de conteúdo de Bardin (2016), considerando os significados presentes, e baseia-se na revisão da literatura, dos documentos e dos dados levantados nos documentos oficiais.

O debate é acerca do "ser" e do "tornar-se humano" por meio da concepção de uma educação humanizadora e problematizadora, a qual a perspectiva freireana defende, da necessidade de possibilitar àqueles historicamente oprimidos a busca pela humanização (FREIRE, 1997), como é o caso dos sujeitos quilombolas.

A desumanização é exprimida e entendida como alienante e dominadora e a humanização é vista como um "projeto utópico" das classes dominadas e oprimidas, implicando "[...] na ação dos homens sobre a realidade social - a primeira, no sentido da preservação do 'status quo'; a segunda, no da radical transformação do mundo opressor" (FREIRE, 1981, p. 79).

A "pedagogia" freireana apresenta imensa relevância na valorização da cultura, das memórias, dos valores, saberes e conhecimentos, especialmente dos conhecimentos prévios, com grande ênfase nos contextos, nas experiências e realidade dos educandos, e da diversidade cultural e intelectual dos sujeitos, contrapondo-se à lógica "bancária" de educação em que uns inferiorizam como uma forma de dominar os outros.

Ademais, proporciona contribuições para a compreensão do ser e do fazer pedagógico, com a centralidade nos sujeitos intrínsecos do processo de ensino-aprendizagem. 
Também possibilita a percepção do ser e fazer do educador e educando e da prática educativa no contexto atual, permeada pelas contradições e diversidades e desigualdades.

Destarte, entende-se de suma importância o debate acerca dos conhecimentos referentes aos povos e/ou comunidades quilombolas e da Educação Escolar Quilombola (EEQ) como uma modalidade de ensino na educação básica, olhando para os estágios curriculares supervisionados, uma vez que são potentes articuladores e integradores da teoria e prática, com as contribuições do ilustre educador Paulo Freire e outros autores acerca da reflexão crítica sobre a teoria e a prática na formação docente.

\section{FORMAÇÃO DOCENTE E SABERES NECESSÁRIOS PARA A AÇÃO EDUCATIVA NA CONTEMPOREIDADE: DIÁLOGOS EM FREIRE}

Feldmann (2009, p. 72), a respeito do ser educador na contemporaneidade, enfatiza:

As pessoas não nascem educadores, se tornam educadores, quando se educam com o outro, quando produzem a sua existência relacionada com a existência do outro, em um processo permanente de apropriação, mediação e transformação do conhecimento mediante um projeto existencial e coletivo de construção humana.

Logo, é na relação mútua, relacional e contextual que surge o educador, nessa relação contraditória entre homens e mulheres. Assim, esse profissional assume um novo contexto e passa a responder os novos desafios de nossa atual sociedade.

A autora lança ainda uma pergunta que nos provoca a pensar sobre a formação do ser humano para a construção de mudanças em quaisquer esferas de atuação: quais as novas exigências da sociedade contemporânea para o professor da escola brasileira e como pensar sua formação? Portanto, a acelerada transformação pela qual o mundo passa, decorrente tanto dos avanços tecnológicos como da incidência de uma nova cultura de trabalho, afeta diretamente o universo escolar.

Dessarte, conforme destaca Feldmann (2008, p. 171), esse processo tornar-se educadores ocorre:

[...] quando produzimos a existência em processo permanente de apropriação, mediação e transformação do conhecimento. Palavras, sentidos que encerram em si a questão da multirreferencialidade, da multidimensionalidade, da complexidade, quando a tomamos como objeto de estudos. Nesse sentido, procura-se situar as dimensões e conflitos do "ser" e do "fazer" do professor em sintonia com a configuração da organização curricular, institucional e cultural da escola, apontando-se a relação entre as transformações da sociedade contemporânea e as mudanças de ordem social e epistemológica que se abrem em novos compromissos ético-pedagógicos a serem assumidos pelos sujeitos que pensam e atuam na escola brasileira.

O conceito de formação docente ou formação de professores está sujeito a múltiplas perspectivas, mas a maioria delas está relacionada ao entendimento de desenvolvimento 
pessoal, de formar profissionais competentes com conteúdo e experiências em sua área de formação. Para Berbaum (apud GARCÍA, 1999, p. 21), a ação de formar professores "[...] corresponde a um conjunto de condutas, de interações entre formadores e formandos, que pode ter múltiplas finalidades [...] ou não, e em relação às quais existe uma intencionalidade de mudança".

Para Zabalza (2014, p. 68), "[...] a formação não tem a ver somente com o desenvolvimento social e econômico, mas também com o desenvolvimento pessoal e social, sendo este vinculado com o sentido da cultura, das vivências". Não se refere a treinamento de professores, mas ao sujeito estar contribuindo para seu próprio processo de formação, a partir dos conhecimentos trazidos ao longo de suas vidas e de suas competências.

O autor sobressai com certa culpabilização, denominada "sociedade do conhecimento", pelo fato de esta transmitir a ideia de que a formação é que vai resolver todas as nossas esperanças tanto no âmbito pessoal quanto no profissional, bem como a inserção no meio do trabalho, emprego e a situação econômica.

O desenvolvimento profissional do professor, segundo Imbernón (2011), é concebido por meio de intenções sistematizadas que visem melhorar a prática, as convicções e os conhecimentos profissionais, com a finalidade de aumento da qualidade: docente, da pesquisa e de gestão. Logo:

O professor precisa de novos sistemas de trabalho e de novas aprendizagens para exercer a sua profissão, e concretamente daqueles aspectos profissionais e de aprendizagem associados às instituições educativas como núcleo em que trabalha um conjunto de pessoas (IMBERNÓN, 2011, p. 47).

"Professor, sujeito que professa saberes, valores, atitudes, que compartilha relações e, junto com o outro, elabora a interpretação e reinterpretação do mundo" (FELDMANN, 2009 , p. 71). A autora realça que o problema que enfrentamos hoje, que é o da articulação entre o pensar e o agir, entre a teoria e a prática, configura-se como importante desafio a ser enfrentado neste tempo de insegurança e incertezas, no processo de formação de professores. Entendemos que teoria e prática não falam por si mesmas, uma vez que a prática é apenas o ponto de partida para a reflexão da prática docente.

Essa incerteza, segundo a autora, está diretamente relacionada à nova configuração dada à educação nos tempos atuais - a formação docente e o mercado de trabalho, pois esta sempre esteve atrelada aos movimentos do mercado, do desenvolvimento tecnológico. Enfatiza-se também que, na articulação entre universidade e escola, a dicotomia entre teoria e prática é vista como um obstáculo na concretização de uma prática pedagógica dialógica e emancipadora dos sujeitos. Destaca ainda que, na contemporaneidade, o professor em sua prática educativa encontra-se cada vez mais desafiado a trabalhar com as questões de diversas naturezas, entre elas a cultural.

García (1999) afirma que os programas de formação de professores tendem a desenvolver apenas a aquisição de determinados conhecimentos: pedagógicos, psicológicos, 
científicos e, por conseguinte, não é dada a devida atenção às questões relacionadas ao contexto, políticas e culturais. Alerta, dessa forma, que é necessário que esses programas de formação inicial de professores desenvolvam conhecimentos para a compreensão da diversidade cultural nos processos do ensinar e aprender, possibilitando a atitude humana, reflexiva e democrática.

A prática docente nunca é vazia nem despreocupada no processo ensino-aprendizagem. Ela é cheia de intenções e de conteúdo, sendo sempre (re)planejada. É necessária ao professor a pesquisa em sua prática para que possa intervir no contexto da escola e comunidade escolar.

A educação, como processo histórico e social, corporifica-se "[...] na relação teoria e prática" (FELDMANN, 2009, p. 79).

Segundo Freire (1996, p. 17-18), no ato de ensinar e aprender, a prática docente necessita ter reflexão crítica que:

[...] envolve o movimento dinâmico, dialético, entre o fazer e o pensar sobre o fazer. O saber que a prática docente espontânea ou quase espontânea, "desarmada", indiscutivelmente produz é um saber ingênuo, um saber de experiência feito, a que falta a rigorosidade metódica que caracteriza a curiosidade epistemológica do sujeito. Este não é o saber que a rigorosidade do pensar certo procura. Por isso, é fundamental que, na prática da formação docente, o aprendiz de educador assuma que o indispensável pensar certo não é presente dos deuses nem se acha nos guias de professores que iluminados intelectuais escrevem desde o centro do poder, mas, pelo contrário, o pensar certo que supera o ingênuo tem que ser produzido pelo próprio aprendiz em comunhão com o professor formador.

$[\ldots]$

[...] O próprio discurso teórico, necessário à reflexão crítica, tem de ser tal modo concreto que quase se confunde com a prática. O seu "distanciamento" epistemológico da prática enquanto objeto de sua análise e maior comunicabilidade exercer em torno da superação da ingenuidade pela rigorosidade.

Pensar sobre formação docente é ponderar acerca da formação do ser humano. Assim sendo, o ensino-aprendizagem é uma prática social viva, dinâmica, por isso é importante a compreensão da atividade docente no contexto da prática social diária. "Para Freire, a docência se constrói, pois a condição de tornar-se professor se estabelece num processo, [...]. Envolve a consciência da sua condição em ação" (STRECK; REDIN; ZITKOSKI, 2017, p. 330).

Freire (1987, apud PEREIRA, 2017, p. 89) entende a prática como reflexão da ação pedagógica. Para ele, somente seremos verdadeiramente críticos se vivermos plenamente essa práxis, nossas ações devem vir de uma reflexão crítica que sistematize nosso modo de pensar, de forma que seja superado o conhecimento "[...] ingênuo" da nossa realidade. Mas essa práxis "não pode ser negada às massas populares porque o objetivo é a sua emancipação"”. 
A teoria e prática crítica permite a problematização e parte da historicidade dos seres humanos, ao contrário da teoria e prática "educação bancária", a qual não reconhece os homens como seres históricos (FREIRE, 1979), assim a educação crítica:

[...] considera os homens como seres em devir, como seres inacabados, incompletos em uma realidade igualmente inacabada e juntamente com ela. Por oposição a outros animais, que são inacabados mas não históricos, os homens sabem-se incompletos. Os homens têm consciência de que são incompletos, e assim, nesse estar inacabados e na consciência que disso têm, encontram-se as raízes mesmas da educação como fenômeno puramente humano. O caráter inacabado dos homens e o caráter evolutivo da realidade exigem que a educação seja "uma atividade contínua”. A educação é, deste modo, continuamente refeita pela práxis. Para ser, deve chegar a ser. Sua duração - no sentido bergsoniano da palavra - encontra-se no jogo dos contrários: estabilidade e mudança. $O$ método bancário põe o acento sobre a estabilidade e chega a ser reacionário. A educação problematizadora - que não aceita nem um presente bem conduzido, nem um futuro predeterminado - enraíza-se no presente dinâmico e chega a ser revolucionária (FREIRE, 1979, p. 42).

Para o autor, a educação problematizadora, por conseguinte, fundamenta-se na criatividade e possibilita a estimulação de uma ação e reflexão que seja autêntica acerca da realidade.

\section{O ESTÁGIO CURRICULAR SUPERVISIONADO, AS COMUNIDADES QUILOMBO- LAS E A EDUCAÇÃO ESCOLAR QUILOMBOLA}

\section{ESTÁGIO CURRICULAR COMO PRÁTICA PROFISSIONAL}

Não é possível adquirir experiência prática apenas nos últimos semestres de um curso de licenciatura, como é o que ocorre nos cursos em geral atualmente. Para nos construirmos docentes, é necessário que compreendamos que isso não é possível apenas observando ou lendo sobre outras experiências. É preciso experimentarmos por meio da vivência em sala de aula, na prática do estágio, e continuamente ao longo da trajetória docente. A formação do ser "professor" não termina na colação de grau, ela é contínua e exige atualização permanente. Deste modo, a disciplina Prática de Ensino e o Estágio Supervisionado não podem " [...] ser um fim na formação do acadêmico, mas sim uma [...] possibilidade de articulação e aprendizagem para além dos componentes curriculares desenvolvidos durante todo o curso, com a atuação na escola e em sala de aula (SAIKI; GODOI, 2015, P. 30).

Para Pereira (2017), o estágio é um componente imprescindível na formação docente, o currículo deve ser "pensado, problematizado", de acordo com a realidade vivenciada dos educandos. No entanto, os currículos nacionais estão antagonicamente condicionados 
pela tradição de formar cidadãos para o convívio em sociedade ou para formar sujeitos com "competências e habilidades" para competição do conhecimento.

Kulcsar (2012, p. 58) alerta para a necessidade de repensar o papel das universidades, principalmente quanto ao redimensionamento do estágio supervisionado obrigatório em todos os currículos das licenciaturas e da pedagogia, pois esse este não é devidamente explorado.

Portanto, a autora sugere que o estágio necessita voltar-se "[...] ao atendimento da comunidade [...]" e possibilitar ao estagiário que se engaje na realidade, de modo a conhecer os desafios do magistério, para permitir reflexões sobre a profissão que vai assumir. "Esse envolvimento, em situações reais vividas, visará primordialmente à integração do saber com o saber" (KULCSAR, 2012, p. 58).

Dessarte, não é possível pensar em estágio sem a articulação entre a teoria e a prática. Nesse sentido, Weisz (2000 apud RIOS, 2010) chama de "tematização da prática" o movimento constante de reflexão - ação - reflexão, que transita pela teoria e pela prática sem provocar a fragmentação desses dois elementos considerados fundamentais no processo formativo, bem como possibilite a construção de aprendizagens sobre o objeto de ensino e as condições didáticas necessárias para que os educandos se apropriem dos conhecimentos necessários.

[...] é no próprio espaço do trabalho que "esperanço" de novo, que retomo com vigor a luta, que encontro possibilidades e alternativas. Auxiliam-me nesse movimento a prática e a reflexão sobre ela, o fazer e o pensar crítico sobre ele, um exercício que mescla razão e paixão (RIOS, 2010, p. 17).

"A prática não fala por si mesma, ela exige uma relação com a teoria para que possamos chegar à compreensão de práxis [...]" (PEREIRA, 2017, p. 87). Para a autora, a prática leva à libertação, por isso ela é a ação-reflexão sobre si mesmo e sobre o mundo para transformá-lo. Desse modo, as ações docentes dependem dessa reflexão acerca do que se vivencia, para agir criticamente, e que o novo pensar possa levar à superação do conhecimento "ingênuo" acerca da realidade em que estamos inseridos, como dizia Paulo Freire.

Sacristán (1999, p. 19), a respeito da articulação entre teoria e prática, tece que: "[...] a relação entre teoria e prática interessa e envolve muitas pessoas e não apenas os especialistas e os docentes. Os teóricos e os práticos são parte desse processo, já que a prática educativa é uma atividade social". O aluno também é um agente ativo, modificador/ pensador nessa relação, que inclui o currículo e que não pode ser compreendido sem pensar em sua influência em sala de aula.

Para o autor, é importante frisar que muita teorização e pesquisa são inconvenientes para a prática, a não ser que outras atividades sejam trazidas e trabalhadas de formas diferentes das habituais, pois, em certos setores do magistério, a teoria é comumente encarada como alheia da realidade e, por isso, torna-se inútil para suas práticas. Entretanto, é a teoria que sustenta o discurso das possibilidades e do que é bom para o progresso, e é isso o que os que estão na prática não percebem, porque estão imersos na produção da realidade vigente. 
Sacristán (1999, p. 19) enfatiza ainda que o pensamento educativo não tem como função apenas explicar, mas também guiar a prática educativa. Portanto, resolver a panaceia da relação teoria-prática é um esforço para conseguir explicar "[...] como, porque e para que da prática educativa [...]". A teoria e a prática abrangem muitos sujeitos, além dos especialistas, porque ela é uma prática social e cultural que exige que se contemplem relações entre todos os envolvidos nessa trama educacional. Ademais, necessita de intencionalidade e participação ativa e efetiva dos sujeitos curriculares.

Assim como destaca Sacristán (2008, p. 65 - grifos do autor):

Toda ação pedagógica e toda prática tem um sentido [...]. As práticas também têm atrás de si alguém (sujeitos individuais ou coletivos) que quiseram realizá-las. [...] Desvendar o mundo dos significados da diversidade ou da diferença e ver o que se quis fazer com elas é um caminho para descobrir práticas, afinar objetivos, tomar consciência e poder administrar os processos de mudança de maneira um pouco mais reflexiva [...].

A Resolução CNE/CP n. ${ }^{\circ}$ 2, de 20 de dezembro de 2019, estabelece: "(a) 400 (quatrocentas) horas para o estágio supervisionado, em situação real de trabalho em escola, segundo o Projeto Pedagógico do Curso (PPC) da instituição formadora; [...]" (BRASIL, 2019, p. 6). Além disso, realça o desenvolvimento do conhecimento em todas as dimensões profissionais, acerca das diferentes modalidades de ensino.

Segundo Silva e Gaspar (2018, p. 206), o estágio supervisionado, além de ser um espaço de aprendizagem da profissão docente, possibilita a construção da identidade profissional e precisa ser:

[...] compreendido como campo de conhecimento e a ele deve ser atribuído um estatuto epistemológico indissociável da prática, concebendo-o como práxis, o que o define como uma atitude investigativa que envolve a reflexão e a intervenção em questões educacionais.

Entende-se, assim, o estágio como um elemento essencial na articulação entre teoria e prática, para o desenvolvimento de conhecimentos acerca das diferentes realidades e contextos educacionais, sobretudo diversos em que os educandos poderão atuar na realização do estágio e no futuro como profissionais.

A EDUCAÇÃO ESCOLAR QUILOMBOLA NOS ESTÁGIOS CURRICULARES SUPERVISIONADOS DAS LICENCIATURAS: ANÁLISE DOS PROJETOS PEDAGÓGICOS DE CURSOS QUANTO À PRESENÇA DA EEQ E POVOS/E OU COMUNIDADES QUILOMBOLAS

No Brasil, existem cerca de cinco mil comunidades quilombolas nas mais diversas regiões, com sua riqueza e diversidade cultural, modos de ser e viver diferenciados, com a 
centralidade na luta pelo território, que Ihes é um direito garantido por lei, entretanto muitas vezes não efetivado.

As comunidades quilombolas representam a resistência, a herança cultural, material e imaterial e, desde o período escravista até hoje, constituem-se como uma forma de organização social, um movimento de âmbito social e político (NASCIMENTO, 1985).

Portanto, os quilombolas existem e resistem na contemporaneidade e, além das lutas pela titulação de suas terras, reivindicam uma educação que valorize sua realidade, assim como a pedagogia freireana realça.

Em 2012, foram estabelecidas as Diretrizes Curriculares Nacionais para a Educação Escolar Quilombola na Educação Básica (DCNEEQ), fruto de reivindicação política do movimento quilombola e do movimento negro.

No entanto, infelizmente, ainda há muito desconhecimento sobre os povos e/ou comunidades quilombolas, que, por vezes, são invisibilizados nos processos educacionais, sobretudo nos currículos e nas práticas educativas.

De acordo com Silva (2020, p. 44): "Os mais de 300 (trezentos) anos de escravização legal no Brasil e os 100 (cem) de negação existencial pelo Estado, sem qualquer lei de amparo ou de proteção dos quilombolas, colocaram os quilombos em profunda invisibilidade".

Apesar de ser dever do Estado a garantia da titulação das terras quilombolas, conforme a Constituição Federal de 1988, em seu art. 68 do Ato das Disposições Constituições Transitórias (ADCT), garantir "[...] aos remanescentes das comunidades dos quilombos que estejam ocupando suas terras é reconhecida a propriedade definitiva, devendo o Estado emitir-lhes os títulos respectivos" (BRASIL, 1988, p. 138), muitas comunidades ainda lutam para que esse direito seja efetivado, assim como para a garantia de outras políticas públicas, como a educação diferenciada que reconheça suas especificidades, relacionadas as suas vivências, modos de ser, fazer e conhecer tradicionais.

De um universo de 45 cursos de Licenciatura oferecidos pela Instituição de Ensino da Rede Federal de Educação, Ciência e Tecnologia, selecionamos para o referido estudo cinco cursos que mencionam no campo específico do estágio curricular supervisionado dos Projetos de Cursos (PPC) a Educação Escolar Quilombola, ou Educação Quilombola como categoria de análise a priori, conforme quadro a seguir: 
Quadro 1 - A educação escolar quilombola ou educação quilombola no estágio curricular supervisionado das Licenciaturas

\begin{tabular}{|c|c|c|c|}
\hline Campus & Curso & $\begin{array}{l}\text { Descrição no item estágio curricular su- } \\
\text { pervisionado - Educação Escolar Qui- } \\
\text { lombola, ou Educação Quilombola }\end{array}$ & $\begin{array}{l}\text { Apresenta a temática } \\
\text { em outro campo do } \\
\text { PPC, inclusive nos } \\
\text { conteúdos, objetivos } \\
\text { e organização curri- } \\
\text { cular. }\end{array}$ \\
\hline Campus 1 & $\begin{array}{l}\text { Licenciatura em Ciên- } \\
\text { cias Biológicas - Im- } \\
\text { plantação } 2015 \text { - Atua- } \\
\text { lização } 2016 \text { /2019 }\end{array}$ & $\begin{array}{l}\text { "[...] podendo contemplar, além do ensino } \\
\text { regular, diferentes modalidades de ensino } \\
\text { - educação de jovens e adultos, educação } \\
\text { especial, educação profissional técnica de } \\
\text { nível médio, educação escolar indígena e } \\
\text { quilombola, educação do campo e educa- } \\
\text { ção a distância. Dessa forma, o estágio po- } \\
\text { derá ocorrer no IFSP e em demais escolas } \\
\text { das redes de ensino pública ou privada" } \\
\text { (PPC - CAMPUS 1, 2019, p. 29). }\end{array}$ & não \\
\hline Campus 2 & $\begin{array}{l}\text { Licenciatura em Letras } \\
\text { - Implantação } 2016 \\
\text { - Atualização } 2019\end{array}$ & $\begin{array}{l}\text { "[...] a carga horária do Estágio Curricular } \\
\text { Supervisionado para o Curso de Letras com } \\
\text { dupla habilitação foi dividida entre as duas } \\
\text { habilitações: [...] em Língua Portuguesa e } \\
\text { suas literaturas [...] em língua estrangeira - } \\
\text { no caso o Espanhol e suas literaturas. Em } \\
\text { ambos os estágios serão comtemplados as } \\
\text { duas modalidades principais da educação } \\
\text { básica - Ensino Fundamental II e Ensino } \\
\text { Médio, outros contextos educacionais di- } \\
\text { versificados - como a educação de jovens } \\
\text { e adultos (EJA), a educação especial, a } \\
\text { educação profissional e técnica, educação } \\
\text { a distância, educação indígena, educação } \\
\text { quilombola e/ou educação à distância - de } \\
\text { acordo com as possibilidades da região, e } \\
\text { a gestão escolar [...]" (PPC - CAMPUS 2, } \\
\text { 2019, p. 39). }\end{array}$ & não \\
\hline Campus 3 & $\begin{array}{l}\text { Licenciatura em Le- } \\
\text { tras/Português } \\
\text { - Implantação } 2019\end{array}$ & $\begin{array}{l}\text { "O aluno poderá vincular seu estágio à } \\
\text { Educação Básica regular, ao Ensino Médio } \\
\text { Integrado ao Técnico, à Educação Profis- } \\
\text { sional, à Educação de Jovens e Adultos } \\
\text { (EJA) e a aulas da Educação Básica [...]. } \\
\text { Poderá também ser cumprida em [...] em } \\
\text { organizações não governamentais ligadas } \\
\text { às camadas excluídas da população, em } \\
\text { movimentos sociais, comunidades quilom- } \\
\text { bolas, aldeias indígenas, enfim, instâncias } \\
\text { que permitam ao estudante conhecer a di- } \\
\text { versidade linguística e compreender como } \\
\text { a desigualdade social se desdobra no país. } \\
\text { [...] Essa participação deve se configurar } \\
\text { como atividade de observação, participa- } \\
\text { ção/intervenção ou regência, desde que } \\
\text { especificada nos referidos projetos de } \\
\text { curso e aprovada pelo Orientador" (PPC - } \\
\text { CAMPUS 3, 2018, p. 34-35). }\end{array}$ & não \\
\hline
\end{tabular}




\begin{tabular}{|c|c|c|c|}
\hline Campus 4 & $\begin{array}{l}\text { Licenciatura em } \\
\text { Química } \\
\text { - Implantação } 2015 \text { - } \\
\text { Atualização } 2019\end{array}$ & $\begin{array}{l}\text { "Acompanhamento, Orientação e Avalia- } \\
\text { ção - De acordo com a Resolução } 19 \text { [...] } \\
\text { de } 14 \text { de maio de } 2019 \text {, os estudantes de- } \\
\text { verão realizar } 400 \text { horas de estágio super- } \\
\text { visionado: Art. } 6 .^{\circ} \text { O estágio será realizado } \\
\text { em escolas de Educação Básica em suas } \\
\text { etapas - educação infantil, ensino funda- } \\
\text { mental, ensino médio - e modalidades - } \\
\text { educação de jovens e adultos, educação } \\
\text { especial, educação profissional e técnica } \\
\text { de nível médio, educação escolar indíge- } \\
\text { na, educação do campo, educação esco- } \\
\text { lar quilombola e educação a distância. [...] } \\
\text { As Diretrizes do Estágio das Licenciaturas } \\
\text { (Resolução [...] n. }{ }^{\circ} 19 / 2019 \text { ) estabelecem a } \\
\text { importância dos estudantes estagiarem em } \\
\text { mais de uma modalidade de ensino [...]" } \\
\text { (PPC - CAMPUS 4, 2017, p. 29-30). }\end{array}$ & não \\
\hline Campus 5 & $\begin{array}{l}\text { Licenciatura em } \\
\text { Matemática } \\
\text { - Implantação } 2010 \\
\text { - Reformulação } 2017\end{array}$ & $\begin{array}{l}\text { "O estágio supervisionado IV se articula } \\
\text { com o componente curricular Prática de } \\
\text { Ensino de Matemática [...] Em outras mo- } \\
\text { dalidades de ensino, deve ser realizado } \\
\text { por meio das atividades de observação e } \\
\text { de participação. Considera-se, para efei- } \\
\text { to desse estágio supervisionado, as ati- } \\
\text { vidades desenvolvidas na Educação de } \\
\text { Jovens e Adultos, na Educação Especial, } \\
\text { no Ensino Médio Integrado, na Educação } \\
\text { do Campo, na Educação Escolar Indígena, } \\
\text { na Educação a Distância e na Educação } \\
\text { Escolar Quilombola, na Educação Escolar } \\
\text { Quilombola (PPC - CAMPUS 5, 2017, p. } \\
182 \text { - grifos nossos). }\end{array}$ & não \\
\hline
\end{tabular}

Fonte: as autoras (2021)

Foi possível observar que dos cinco cursos analisados de cinco áreas do conhecimento - ciências biológicas, letras (português, português/inglês) química e matemática três cursos (Campus 1, Campus 4 e Campus 5) apresentam de forma ampla a educação escolar quilombola como modalidade da educação como uma possibilidade de realização do estágio supervisionado. Um dos cursos (Campus 2) apresenta a educação quilombola como "outros contextos educacionais diversificados". E um cursos (Campus 3) menciona as comunidades quilombolas entre outras, ligadas à organização social de "camadas excluídas", porém não como uma modalidade de ensino. Entretanto esses conhecimentos não são desenvolvidos ao longo de toda a formação, inclusive o do Campus 5 que traz o estágio supervisionado articulado com o componente curricular Prática de Ensino de Matemática, porém este não faz nem uma menção a questão quilombola.

Embora o documento mencionado a seguir, estabeleça as Diretrizes para Estágio das Licenciaturas da referida Instituição, e apresente a EEQ como uma modalidade de ensino em que se pode desenvolver o estágio, em seu Art. 15: 
[...] No desenvolver do estágio, a diversidade de atuação docente deverá ser garantida e, para tanto, deverão ser desenvolvidas atividades contemplando as diferentes etapas da Educação Básica para as quais o futuro professor estará apto, e, preferencialmente, mais de uma modalidade de ensino, a saber:

I. São etapas de ensino: Educação Infantil, Ensino Fundamental e Ensino Médio quando a área do curso estiver presente;

II. São modalidades de ensino: Educação Profissional Técnica de Nível Médio, Educação de Jovens e Adultos (EJA), Educação a distância (EAD), Educação Especial, Educação Escolar Indígena, Educação do Campo, Educação Escolar Quilombola e Ensino Regular (SÃO PAULO, 2019, p. 9-10 - grifo nosso).

É notória, ainda, a incipiência dos conhecimentos relacionados ao povo e/ou comunidades quilombolas no campo das pautas educacionais, conforme se destaca a respeito da invisibilidade da Educação Escolar Quilombola e sua total escassez nos currículos, assim como no campo das produções acadêmicas, segundo o "Texto-referência para a elaboração das Diretrizes Curriculares Nacionais para a Educação Escolar Quilombola":

A invisibilidade, o desconhecimento e a escassa produção teórica no campo educacional sobre a Educação Escolar Quilombola levam a sua total inexistência nos currículos de graduação. Também não se pode dizer que, na produção teórica educacional, tenhamos, até o momento, um corpo significativo de dissertações e teses e pesquisas acadêmicas que elegem a questão quilombola como tema de investigação e estudo (BRASIL, 2011, p. 35).

Além disso, destacam-se ainda, diversas necessidades urgentes no campo da formação de professores para a EEQ:

a) a inserção das discussões sobre a realidade quilombola nos cursos de licenciatura e pedagogia de todo o país;

b) a formação inicial de professores quilombolas para sua atuação preferencial em escolas quilombolas;

c) a formação inicial de professores quilombolas para sua atuação em escolas não quilombolas;

d) a formação inicial de professores leigos, quilombolas ou não, que já atuam em escolas localizadas nas regiões quilombolas;

e) a formação inicial de professores leigos, quilombolas ou não, que já atuam em escolas que atendem a crianças, adolescentes, jovens e adultos quilombolas juntamente com outros estudantes (BRASIL, 2011, p. 35-36).

Acerca da invisibilidade de determinados sujeitos no currículo, Santomé (2013) assinala que culturas são invisibilizadas e apagadas no currículo escolar e em muitas vezes não dá a devida atenção às diversidades, incorrendo em atitudes de "currículos turísticos", que por vezes reproduzem estereótipos e deformações acerca das temáticas, isso quando não abordam superficialmente em apenas um dia específico ou unidade didática, como ob- 
servou-se nos PPC em que menciona a EEQ somente no campo do estágio, sem a devida contextualização e articulação.

Conquanto a EEQ tenha sido reconhecida como uma modalidade da Educação Básica que requer uma "pedagogia própria", respeito a diversidade étnico-racial e cultural, em 2010, por meio das Diretrizes Curriculares Nacionais para a Educação Básica e a necessidade do ensino da história dos quilombos, já apresentada nas Diretrizes Curriculares Nacionais para a Educação das Relações Étnico-Raciais e para o Ensino de História e Cultura Afro-Brasileira e Africana (BRASIL, 2004) na "História e Cultura Afro-Brasileira e Africana - Determinações" em "Ações Educativas de Combate ao Racismo e a Discriminações", as quais, estabelecem que:

O ensino de História Afro-Brasileira abrangerá, entre outros conteúdos, iniciativas e organizações negras, incluindo a história dos quilombos, a começar pelo de Palmares, e de remanescentes de quilombos, que têm contribuído para o desenvolvimento de comunidades, bairros, localidades, municípios, regiões (exemplos: associações negras recreativas, culturais, educativas, artísticas, de assistência, de pesquisa, irmandades religiosas, grupos do Movimento Negro). Será dado destaque a acontecimentos e realizações próprios de cada região e localidade.

[...] os sistemas de ensino e os estabelecimentos de Educação Básica, nos níveis de Educação Infantil, Educação Fundamental, Educação Média, Educação de Jovens e Adultos, Educação Superior, precisarão providenciar:

- Registro da história não contada dos negros brasileiros, tais como em remanescentes de quilombos, comunidades e territórios negros urbanos e rurais.

[...] - Divulgação, pelos sistemas de ensino e mantenedoras, com o apoio dos Núcleos de Estudos Afro-Brasileiros, de uma bibliografia afro-brasileira e de outros materiais como mapas da diáspora, da África, de quilombos brasileiros, fotografias de territórios negros urbanos e rurais, reprodução de obras de arte afro-brasileira e africana a serem distribuídos nas escolas da rede, com vistas à formação de professores e alunos para o combate à discriminação e ao racismo (BRASIL, 2004, p. 23-25 - grifos nossos).

Tais aspectos são reforçados por meio da publicação do principal marco legal da EEQ, a Resolução CNE/CEB n. ${ }^{\circ}$ 8, de 20 de novembro de 2012, que define Diretrizes Curriculares Nacionais para a Educação Escolar Quilombola na Educação Básica (DCNEEQ). Todavia, ainda se percebe um total desconhecimento acerca dessa modalidade de ensino que perpassa todos os níveis e modalidades, bem como sobre os povos e/ou comunidades quilombolas, conforme destaca a referida resolução. Especialmente nos cursos de formação de professores, observou-se que, além da menção, não há um aprofundamento no que tange o tema em questão nos currículos analisados.

Segundo (BRASIL, 2011, p. 8 - grifos nossos):

A Educação Escolar Quilombola não pode prescindir da discussão sobre a realidade histórica e política que envolve a questão quilombola no país. Dessa forma, os sistemas de ensino, as escolas, os docentes, os processos de formação inicial 
e continuada de professores da Educação Básica e Superior, ao implementarem as Diretrizes Curriculares Nacionais para a Educação Escolar Quilombola, deverão incluir em seus currículos, além dos aspectos legais e normativos que regem a organização escolar brasileira, a conceituação de quilombo; a articulação entre quilombos, terra e território; os avanços e os limites do direito dos quilombolas na legislação brasileira; a memória; a oralidade; o trabalho e a cultura.

[...] o reconhecimento de comunidades remanescentes de quilombos e seu grande número colocam aos sistemas de ensino e ao Estado o desafio de repensar a educação escolar e seu currículo considerando os valores, as práticas culturais e os conhecimentos produzidos pelas comunidades negras rurais e urbanas ao longo da história do nosso país. A gestão educacional e a formação de professores são indagadas a responder: que tipo de escola e que tipo de educação são necessários às comunidades remanescentes de quilombos no Brasil?

O Parecer CNE/CEB n. ${ }^{\circ}$ 3/2021- Reexame do Parecer CNE/CEB n. ${ }^{\circ}$ 8, de 10 de dezembro de 2020, que tratou das Diretrizes Nacionais Operacionais para a garantia da Qualidade das Escolas Quilombolas (aguardando homologação), enfatiza entre as conquistas e desafios dos movimentos negros e quilombolas:

\footnotetext{
O outro desafio que passou a nortear as lutas do movimento negro foi a inserção da realidade histórica e cultural quilombola nas questões curriculares das escolas de todo o país, culminando, mediante participação qualificada de lideranças, na formulação de disposições propositivas, discutidas em instâncias coletivas regionais, alcançando conquistas a partir da promulgação da Lei n. ${ }^{0} 10.639$, de 9 de janeiro de 2003. Esse marco legal considera e assegura que as comunidades quilombolas fazem parte da história e da composição da sociedade brasileira e, portanto, necessitam ser inseridas na produção historiográfica e no trabalho docente (BRASIL, 2021, p. 3-4).
}

Apesar desses apontamentos, é nítido que, mesmo que a Lei 10.639/2003 tenha assegurado que as comunidades quilombolas são constituintes da sociedade brasileira e da necessidade de inserirem-se na história e no trabalho docente, há ainda um apagamento delas nos currículos.

\section{CONSIDERAÇÕES FINAIS}

Evidenciamos por meio deste estudo que ainda há um desconhecimento referente à $E E Q$, bem como dos povos e/ou comunidades quilombolas, especialmente nos currículos de formação de professores, assim como na prática do estágio supervisionado

Dos currículos (PPC) ora analisados, no que tange ao conhecimento a respeito da prática profissional do estágio supervisionado, apenas quatro citam a EEQ e um as comunidades quilombolas de forma superficial, sem o devido aprofundamento, bem como não desenvolvem os conhecimentos necessários sobre essa modalidade de ensino e as comunidades quilombolas ao longo da formação, o que pode incorrer no despreparo desses 
professores para atuarem com essa modalidade de ensino, reforçando-se a insuficiência da EEQ na formação desses professores, como já apresentado em 2011 quando se discutia a elaboração das DCNEEQ.

Portanto, é necessário aprofundar a compreensão dos mecanismos de articulação entre a teoria e a prática em sala de aula nas escolas durante os estágios, o que, de fato, contribui para a formação integral construção de um docente crítico e reflexivo de sua prática e ação pedagógica, assim como para as diversidades que permeiam o cotidiano escolar.

O estágio é compreendido como "tempo de aprendizagem", e não é exclusivo dos espaços escolares, mas de todo o processo educativo e formativo dos sujeitos que requer intencionalidade e planejamento do ato pedagógico.

O ato de educar não é neutro, e sim crítico, político e filosófico e, da mesma maneira que as diferentes vinculações de uma sociedade que atuam na educação, por ela é possível formar cidadãos políticos, críticos, cientes e conscientes do processo histórico, científico, econômico, cultural e social, capazes de, munidos de conhecimentos múltiplos, transformar a sociedade de acordo com seus interesses e suas necessidades. Uma educação verdadeiramente libertadora, crítica e problematizadora, conforme preconiza Freire.

No tocante à EEQ, essa modalidade de educação precisa de um olhar mais atento nos currículos de formação de professores, especialmente no campo do estágio, uma vez que os licenciandos precisam estar preparados com os conhecimentos necessários acerca da realidade quilombola para a atuação nessa modalidade da educação básica, e tal conhecimento não é evidenciado ao longo do curso. Além disso, uma educação antirracista e humanista, comprometida com a pauta da diversidade cultural de todos os povos, que são historicamente excluídos e invisibilizados nos processos educacionais. 


\section{REFERÊNCIAS}

BARDIN, Laurence. Análise de conteúdo. Tradução de Luís Antero Reto, Augusto Pinheiro. São Paulo: Edições 70, 2016.

BRASIL. Constituição (1988). Constituição da República Federativa do Brasil de 1988. Disponível em: http://www.planalto.gov.br/ccivil_03/constituicao/constituicao.htm. Acesso em: 1. ${ }^{\circ}$ abr. 2021.

BRASIL. Ministério da Educação. Diretrizes Curriculares Nacionais para a Educação das Relações Étnico-Raciais e para o Ensino de História e Cultura Afro-Brasileira e Africana. 2004 Disponível em: https://download.inep.gov.br/publicacoes/diversas/temas_interdisciplinares/diretrizes_curriculares_nacionais_para_a_educacao_das_relacoes_etnico_raciais_e_para_o_ensino_ de_historia_e_cultura_afro_brasileira_e_africana.pdf. Acesso em: 11 ago. 2021.

BRASIL. Ministério da Educação. Diretrizes Curriculares Nacionais Gerais para a Educação Básica. PARECER CNE/CEB n. ${ }^{\circ}$ 7/2010. Disponível em: http://portal.mec.gov.br/index.php?option=com_docman\&view=download\&alias=5367-pceb007-10\&category_slug=maio-2010-pdf\&ltemid=30192. Acesso em: 7 ago. 2021.

BRASIL. Ministério da Educação. Resolução CNE/CEB n. 4, de 13 de julho de 2010. Define Diretrizes Curriculares Nacionais para a Educação Básica. Disponível em: http://portal.mec.gov. br/index.php?option=com_docman\&view=download\&alias=6704-rceb004-10-1\&category_slug=setembro-2010-pdf\&Itemid=30192. Acesso em: 14 ago. 2021.

BRASIL. Conselho Nacional de Educação. Câmara da Educação Básica. Texto-referência para a elaboração das Diretrizes Curriculares Nacionais para a Educação Escolar Quilombola. 2011. Disponível em: http://portal.mec.gov.br/index.php?option=com_docman\&view=download\&alias=8527-texto-referencia-diretrizes-curriculares-educacao-quilombola-cne2011-pdf\&ltemid=30192. Acesso em: 5 mai. 2021.

BRASIL. Ministério da Educação. Diretrizes Curriculares Nacionais para a Educação Escolar Quilombola. Parecer CNE/CEB n. ${ }^{\circ}$ 16/2012. 2012a. Disponível em: http://portal.mec.gov.br/index. php?option=com_docman\&view=download\&alias $=11091-$ pceb016-12\&ltemid=30192. Acesso em: 14 ago. 2021.

BRASIL. Ministério da Educação. Resolução CNE/CEB n. ${ }^{8}$, de 20 de novembro de 2012. Define Diretrizes Curriculares Nacionais para a Educação Escolar Quilombola na Educação Básica. 2012b. Disponível em: http://portal.mec.gov.br/index.php?option=com_docman\&view=download\&alias=11963-rceb008-12-pdf\&category_slug=novembro-2012-pdf\&Itemid=30192. Acesso em: 27 abr. 2021.

BRASIL. Ministério da Educação. Resolução CNE/CP n. 2, de 20 de dezembro de 2019. Define as Diretrizes Curriculares Nacionais para a Formação Inicial de Professores para a Educação Básica e institui a Base Nacional Comum para a Formação Inicial de Professores da Educação Básica (BNC-Formação). http://portal.mec.gov.br/docman/dezembro-2019-pdf/135951-rcp002-19/ file. Acesso em: 19 ago. 2021.

BRASIL. Ministério da Educação. Parecer CNE/CEB n. ${ }^{\circ}$ 3/2021. Reexame do Parecer CNE/CEB n. ${ }^{\circ}$ 8, de 10 de dezembro de 2020, que tratou das Diretrizes Nacionais Operacionais para a garantia da 
Qualidade das Escolas Quilombolas. 2021. Disponível em: http://portal.mec.gov.br/index.php?option=com_docman\&view=download\&alias=191141-pceb003-21\&category_slug=junho-2021-pdf\&Itemid=30192. Acesso em: 19 ago. 2021.

FELDMANN, Marina Graziela. A questão da formação de professores e o ensino de arte na escola brasileira: alguns apontamentos. 2008, p. 169-182. Disponível em: http://www.uepg.br/olhardeprofessor. Acesso em: 16 ago. 2021.

FELDMANN, Marina Graziela (org.). Formação de professores e cotidiano escolar. In. FELDMANN, Maria Graziela. Formação de professores e a escola na contemporaneidade. São Paulo. Editora Senac, 2009. p. 71-81.

FREIRE, Paulo. Conscientização: teoria e prática da libertação: uma introdução ao pensamento de Paulo Freire. Tradução de Kátia de Mello e Silva. Revisão técnica de Benedito Eliseu Leite Cintra. São Paulo: Cortez \& Moraes, 1979.

FREIRE, Paulo. Ação cultural para a liberdade e outros escritos. 5. ed. Rio de Janeiro: Paz e Terra, 1981.

FREIRE, Paulo. Pedagogia da autonomia: saberes necessários à prática educativa. São Paulo: Paz e Terra, 1996.

FREIRE, Paulo. Papel da educação na humanização. Revista da FAEEBA, Salvador, n. 7, jan./jun. 1997.

GARCIA, Carlos Marcelo. Formação de professores para uma mudança educativa. Portugal: Porto Editora, 1999.

IMBERNÓN, Francisco. Formação docente e profissional: formar-se para a mudança e a incerteza. 9. ed. São Paulo: Cortez, 2011.

KULCSAR, Rosa. O estágio supervisionado como atividade integradora. In: PICONEZ, Stela C. Bertholo et al. (coord.) A prática de ensino e o estágio supervisionado. 24. ed. Campinas: Papirus, 2012.

LÜDKE, Menga; ANDRÉ, Marli Elisa. Pesquisa em educação: abordagens qualitativas. São Paulo: EPU, 1986.

MARCONI, Marina de Andrade; LAKATOS, Eva Maria. Técnicas de pesquisa: planejamento e execução de pesquisas, amostragens e técnicas de pesquisa, elaboração, análise e interpretação de dados. 2ª . ed. São Paulo: Atlas, 2003.

NASCIMENTO, Maria Beatriz. O conceito de quilombo e a resistência cultural negra. Afrodiápora: Revista do Mundo Negro, n. 6-7, p. 41-49, 1985. Disponível em: https://issuu.com/institutopesquisaestudosafrobrasile/docs/afrodi_spora_-_volume_6_e_7. Acesso em: 12 abr. 2021.

PEREIRA, Ana Lúcia Nunes. O Estágio Curricular Supervisionado em espaços não escolares no curso de Pedagogia da Universidade do Estado da Bahia (UNEB): as contribuições no percurso formativo. 2017. Tese (Doutorado em Educação: Currículo) - Pontifícia Universidade Católica de São Paulo, São Paulo, 2017. 
RIOS, Terezinha Azerêdo. Compreender e ensinar: por uma docência da melhor qualidade. 8. ed. São Paulo: Cortez, 2010.

SACRISTÁN, José Gimeno. Poderes instáveis em educação. Tradução de Beatriz Affonso Neves. Porto Alegre: Artes Médicas Sul, 1999.

SACRISTÁN, José Gimeno. A construção do discurso da diversidade e as suas práticas. In: PARASKEVA, João M. (org.). Educação e Poder: abordagens críticas e pós-estruturais. Mangualde: Edições Pedago, 2008. p. 69-95.

SAIKI, Kim; GODOI, Francisco Bueno de. A prática de ensino e o estágio supervisionado. In: PASSINI, Elza Y; PASSINI, Romão; MALYSZ, Sandra T. (org.). Prática de ensino de geografia e estágio supervisionado. São Paulo: Contexto, 2015.

SÃO PAULO (Estado). Resolução n 19 IFSP de 14 de Maio de 2019 - Referenda a resolução $n^{\circ} 16 / 2019$, de 06 de maio de 2019, a qual Aprova ad referendum as Diretrizes do Estágio das Licenciaturas. 2019. Disponível em: <https://ifsp.edu.br/acoes-e-programas/66-colegiados/conselho-superior/800-resolucoes-2019>. <https://www.ifsp.edu.br/images/pdf/PDI1923/PDI-2019-2023_Aprovado-CONSUP-12.03.2019-valendo.pdf>. Acesso em: 21 jul. 2021.

SANTOMÉ, Jurjo Torres. As culturas negadas e silenciadas no currículo. In: SILVA, Tomaz Tadeu da (org.). Alienígenas na sala de aula. 11. ed. Petrópolis: Vozes 2013. p. 155-172.

SILVA, Givânia Maria da. Quilombos, práticas e organização de mulheres em Conceição das CriouIas/PE. In: MELLO, Luiz; GONÇALVES, Eliane (org.). Diferenças, desigualdades e violências: olhares sociológicos. Revisão Lídia Freitas. Goiânia: Cegraf UFG, 2020. E-book. Disponível em: https:// files.cercomp.ufg.br/weby/up/688/o/Diferen\%C3\%A7as_desigualdades_e_violencias.pdf. Acesso em: 22 ago. 2021.

SILVA Haíla Ivanilda; GASPAR, Mônica. Estágio supervisionado: a relação teoria e prática reflexiva na formação de professores do curso de Licenciatura em Pedagogia. 2018. Disponível em: https://www.scielo.br/j/rbeped/a/hX97HhvkMZnDnkxLyJtVXzr/?format=pdf\&lang=pt. Acesso em: 21 ago. 2021.

STRECK, Danilo R.; REDIN, Euclides; ZITKOSKI, Jaime José (org.). Dicionário Paulo Freire. 3. ed. Belo Horizonte: Autêntica, 2017.

ZABALZA, Miguel A. O estágio e as práticas em contextos profissionais na formação universitária. São Paulo: Cortez, 2014. 